\title{
NON-DESTRUCTIVE CONTROL METHOD OF THE STATE OF OBJECTS OPERATING LONG TIME
}

\author{
Liudmyla TRYKOZ ${ }^{1}$, Svetlana KAMCHATNAYA ${ }^{1}$, Vitalii LYUTY $^{1}$, Dmytro BORODIN ${ }^{1}$, Armen ATYNIAN ${ }^{2}$ \\ ${ }^{1}$ Ukrainian State University of Railway Transport, Faculty of Construction, Feuerbach square, 7, 61050 Kharkiv, \\ Ukraine, e-mail: 1vtrikoz@ukr.net, kamchatnayasn@gmail.com, LYTIJ_VA@kart.edu.ua, \\ dimitriy.graf@kart.edu.ua \\ ${ }^{2}$ O.M.Beketov National University of Urban Economy, Department of Construction Technology and Building \\ Materials, 17, Marshal Bazhanov Street, 61002 Kharkiv, Ukraine, e-mail: armen010981@mail.ru
}

\begin{abstract}
The development of a diagnostic system is a complex engineering problem aimed at preventing damage caused by deteriorating properties of the materials and structures. This article presents the method of nondestructive testing of change control of concrete structures. The analysis of literature data shows that the overwhelming majority of studies are devoted to the change in electrical resistance of concrete in the collection of its strength, and practically no analogous studies regarding its aging are presented. Theoretical substantiation of the change in electrical concrete characteristics (conductivity, resistance) is given with a change in its strength. A work over-bridge in operation more than 30 years has been surveyed. The experimental part consisted in measuring the electrical potentials on the bridge structures, as well as in determining the strength of the material at the same points. Correlation dependence between the measured electric potential value and the strength of the samples taken from the bridge structures were obtained.
\end{abstract}

Keywords: non-destructive control method, strength, electric potential, concrete

\section{INTRODUCTION}

Railways and facilities located on them bridges, tunnels, and culverts - are important elements of the infrastructure on which the sustainable operation of the entire industry depends. However, an unsatisfactory monitoring system can lead to the detection of irreversible damage, when the cost of repair becomes comparable with the cost of replacement. It is especially important to obtain reliable and comprehensive information about objects that are in operation for a long time. Therefore, a timely and accurate assessment of the current state of the facility is an actual problem. Visual inspection is the most common method for assessing the current state of objects, but its effectiveness depends on the experience and knowledge of the inspector. To increase objectivity, a very wide range of non-destructive testing methods are currently used, including for bridges [15]. The most accurate information on the state of the building material is provided by destructive testing methods conducted in testing laboratories. In most cases it is possible to assess the state of the acting object only by using a non-destructive method. It is shown in [2] that there is a correlation between the results of destructive and nondestructive testing methods for a complex assessment of the state of the structure of an object.

The operation of building structures under operating conditions of their quality deteriorates due to the aggressive influence of the external environment - loads, temperature, humidity, etc. The most dangerous factor in this case is humidity. Any material, when wetting, decreases its durability. Water, when freezing, increases in volume causing the appearance of micro cracks. Water is a universal solvent serving as a conductor for acids and alkalis to enter the material. That is why great attention in works $[3,4,6,7,20]$ was paid to measuring the humidity of various building objects as a basis for monitoring their condition. The same principle was used as a basis for dynamic landslide monitoring in [21], where the correlation between the stability of landslides, rainwater infiltration and underground hydrogeology was determined. Such dynamic monitoring can provide preliminary information on critical shifts and be used for stability analysis and landslide prediction. The purpose of this work is to establish the relationship between the electro physical characteristics of the material and its strength to create a system for early diagnosis of deterioration in the properties of the structure.

\section{METHODOLOGY SELECTION JUSTIFICATION}

In accordance with [5], the object operation is considered as a physical quality with Joule $\times$ second unit of measurement, which can be represented by dependence similar to that in classical or quantum mechanics. In the case of applying the proposed interpretation of the operation of an object in which 
energy changes occur, each work can serve as information carrier about the state of this system, that is, be a diagnostic signal. There are several physical phenomena on which diagnostic methods are based. In [13] basic attention is paid to the application of the shock echo method for full-scale tests carried out on concrete console cantilever beams and a floor fryer. The phenomenon of wave propagation caused by impact is used in the method, and is recorded by one or two accelerometers. Experimental studies have proved shock echo method applicability to detect damage in the concrete structural elements under consideration. The average value of wave speed was $4352 \mathrm{~m} / \mathrm{s}$. It was shown that wave speed was smaller than $90 \%$ of average values in damaged areas. After injection an epoxy resin the distribution of wave speeds became regular and hold in the range of $88 \%$ to $110 \%$ of the average values. The appearence of additional frequency peaks at $17.0898 \mathrm{kHz}$ and $22.2779 \mathrm{kHz}$ indicated reflection of wave from internal defects at the depth about 10 $\mathrm{cm}$ (from $8.96 \mathrm{~cm}$ to $11.84 \mathrm{~cm}$ ). Simulation of deterioration in the properties of building materials on the basis of measuring the velocity of surface Rayleigh waves for two marbles is presented in [17]. The Rayleigh wave measurement method does not require a binding medium between a stone and an ultrasonic probe and is $100 \%$ non-destructive. The material aging was modeled by Freeze and Thaw cycles. Values of surface wave velocities changed from $1500 \mathrm{~m} / \mathrm{s}$ (for 20 cycles) to $1300 \mathrm{~m} / \mathrm{s}$ (for 100 cycles). It is shown that the exponential law can be used to model the degradation processes of elastic properties of the materials under test. The main feature of the above methods is the need of object thumping, which cannot always be realized in the field. In this case, the most promising method for diagnosing material properties is the measurement of electrical characteristics: resistance, conductivity, dielectric permittivity, etc.

As mentioned above the aggressive influence of acids and alkalis decreases the concrete strenght and its durability. Electrical resistivity is an important characteristic of concrete because it allows evaluation of the accessibility of aggressive agents prior to the beginning of the corrosive process and estimation of the corrosion propagation. The study [9] investigated the apparent electrical resistivity of concrete mixes using Wenner's four-electrode method. Larger amounts of slag resulted in increased electrical resistivity and decreases in the electrical conductivity of the pore solution, when compared to the reference concretes. The mixture made of $50 \%$ slag and $50 \%$ white Portland cement showed, on average, compressive resistance levels between $35 \mathrm{MPa}$ and $60 \mathrm{MPa}$, electrical resistivity values that were approximately five times greater. The durability of concrete is strongly influenced by its transport properties, which may be described by its permeability and diffusion characteristics.
Therefore, it very important to be able to predict and control the transport properties of concrete in order to improve its characteristics. The electrical conductivity and microstructure of cement paste over a range of water to cement ratios was investigated in the study [8]. It was shown that it is possible to predict the chloride ingress by measurements of the electrical conductivity. Furthermore, according to [11], electrical resistivity data and testing procedure provide multiple promising options for long lasting bridge decks due to its ease of implementation, repeatability, nondestructive nature, and low cost. Data testify that electrical resistivity can be the chloride ion permeability criteria. For example, the surface resistivity less than $12 \mathrm{Kohm}-\mathrm{cm}$ corresponds to the high permeability while the resistivity more than $254 \mathrm{Kohm}-\mathrm{cm}$ corresponds to the negligible one.

Electrical conductivity is an effective parameter to monitor the microstructural features of cementbased materials. Non-invasive determination of the pore structure features, through the use of electrical response, was discussed in the paper [14]. Changes taking place in cementitious materials as a result of the hydration process were monitored based on the change in conductivity with time. The initial and final setting times of cement pastes predicted using electrical property based methods are very close to the measured values, showing that conductivity is an effective tool to monitor the process in plain and modified systems. The evolution of total porosity in the selected cement paste and concrete systems is predicted using electrical property and is found to match well with the experimental values. The capacity of cement paste without polycarboxylic ether was $1.0 \mathrm{~S} / \mathrm{m}$, after the addition of polycarboxylic ether became $2.0 \mathrm{~S} / \mathrm{m}$. With the increasing emphasis on characterizing concrete durability, a more detailed understanding of the evolution of pore structure features (porosity, pore sizes, and pore connectivity) of cement based materials is being sought. In this context, electrical conductivity measurements emerge as an effective strategy. Electrical conductivity of cement based materials is dependent on the porosity, pore connectivity and the conductivity of the pore solution, all of which are significant in dictating the durability of the material.

In [16], a non-destructive testing method was developed to monitor the hydration process and predict the strength of cement materials using radar and non-contact electrical resistance. These two instruments allow to measure a relative dielectric constant, relative amplitude of the reflected electromagnetic wave and electrical conductivity. The results show that both the relative amplitude and the relative dielectric constant are ideal indicators of the hydration process. The authors [16] obtained linear relations between dielectric properties and compressive strength and proposed a theoretical model to describe this relationship on the basis of measurements of the dielectric constant 
and relative amplitude at an early age. The relative dielectric constant increases from 9 to 12 while the compressive strength decreases from $50 \mathrm{MPa}$ to 10 $\mathrm{MPa}$ respectively. Similar studies, for example [19], help to better understand the hydration process and help to control the quality of cement-based materials. Similarly, you can control the quality of more complex materials, such as concrete [12]. Compressive strength, tensile strength, bending strength, and electrical resistivity of concrete mixtures were tested at different times of their solidifying. The obtained strength dependences from electrical resistance have a hyperbolic character and allow predicting the properties of hardening concrete mixtures with a $4-5 \%$ error. On average, the electrical resistivity rises from 5 to 30 $\Omega \mathrm{m}$ within 28 days of concrete hardening. The relationship between strength and electrical resistance is explained in [10]. When cement hydrates, the volume and pore size decrease, decreasing the volume ratio of the conductive path. Therefore, changes in the electrical properties of concrete can indicate a change in its structure. It can be seen that most of the decreas in conductivity occurred during the first week after casting from $800 \mathrm{uS} / \mathrm{sm}$ to $200 \mathrm{uS} / \mathrm{sm}$. Reverse processes in the pores of concrete occur when working with concrete structures under load. Concrete leaching leads to dissolution of cement hydration products, removal of dissolved ions to the surface. The volume and size of the pores increase with concrete "aging", thus, electrical characteristics also change. The foregoing is the physical justification of the correlation dependencies between these phenomena.

Concrete electrical potential can be measured using a number of methods, but the most common is placing a sample between two electrodes. The electrodes can contact the sample directly or through an electrolytic contact. In the work measurements were made on direct current using a two-electrode method. As an electrode for measuring potentials on the surfaces of structures, a metal rod electrode was pressed against the surface with a sponge moistened with copper sulfate (Fig. 1).

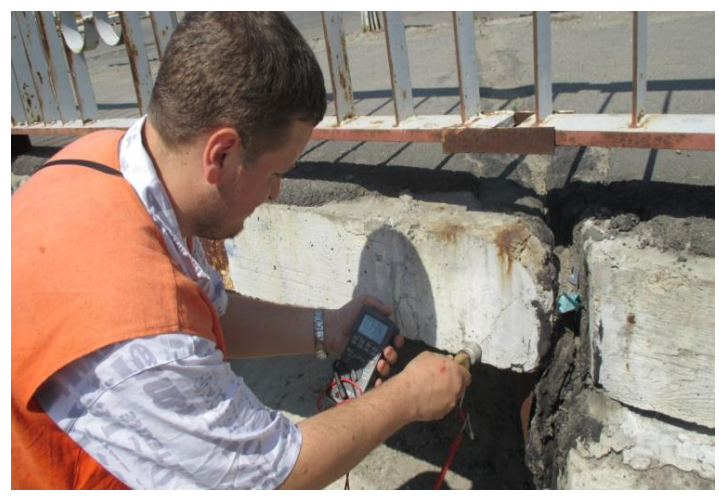

Fig. 1. Measurement of potentials at the site
The measurements were carried out with a multimeter with $0 \div 1000 \mathrm{~V}$ measurement range, $0.01 \mathrm{mV}$ resolution, and $0.08 \%$ error.

\section{OBJECT OF RESEARCH}

The technique was applied on a road overpass (Figure 2). This object was chosen not by chance, since it is an illustrative example of imposing several impacts, which are traditionally neglected in calculating the durability of structures in view of their insignificance, but which, when combined, lead to unforeseen consequences and destruction of structures. In addition to a busy traffic route on the overpass, including cargo, a trolleybus line, power transmission line, and also light supports are attached to the beams with the help of embedded parts. A railway electrified track and a lively avenue section with one-way traffic towards the center in 2 lanes pass under the freeway junction, on which a trolleybus line is also located. A motorway and the railway track are at different levels and separated with a retaining wall.

Span structures are reinforced concrete beams. 8 beams were mounted in the span cross section. Frame type supports of 9 spans were welded with a monolithic bolt. The basis was natural. To study the properties of the materials of the overpass, the characteristic places were identified with the assignment of such ciphers: the slabs of the abutment paving (the lower part is No. 1, the upper part is No. 2); retaining wall is old (outer part is No. 3 , inner part is No. 4); the retaining wall is new (the outer part is No. 5, the inner part is No. 6); support column (the outside part is No. 7, the inner part is No. 8), main plate (No. 9), outer console (No. 10) (Figures 3, 4, 5).

The electric potentials were measured as the difference of potentials between the said construction surfaces and ground behind the overbridge. The metal rod electrode was pressed against the surface which had been cleared from dust and mud. As another electrode a metal rod was used that was dipped into the ground at the depth $1.5 \mathrm{~m}$ and at a distance of $50 \mathrm{~m}$ from the consrtuction. The measurement procedure was similar to [1].

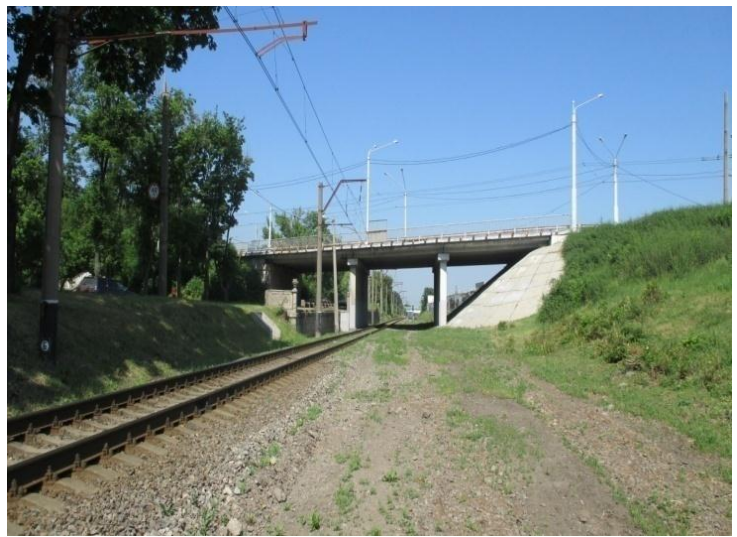

Fig. 2. Over-bridge main view 


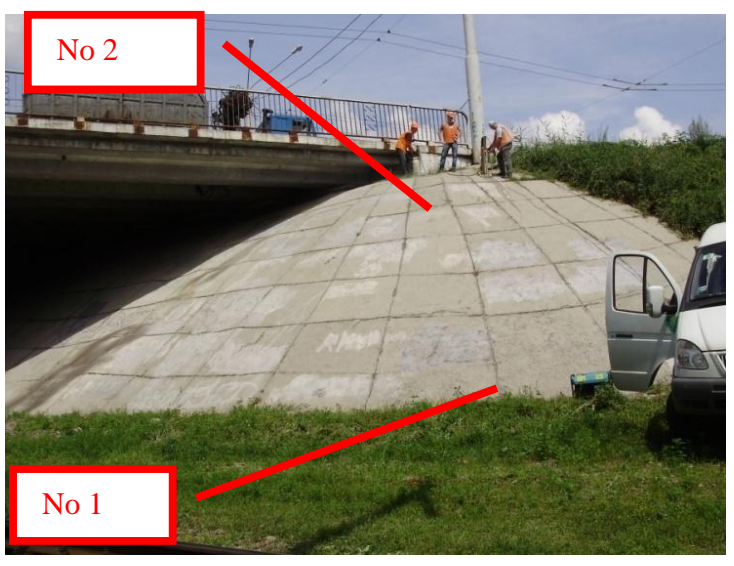

Fig. 3. Abutment sample points

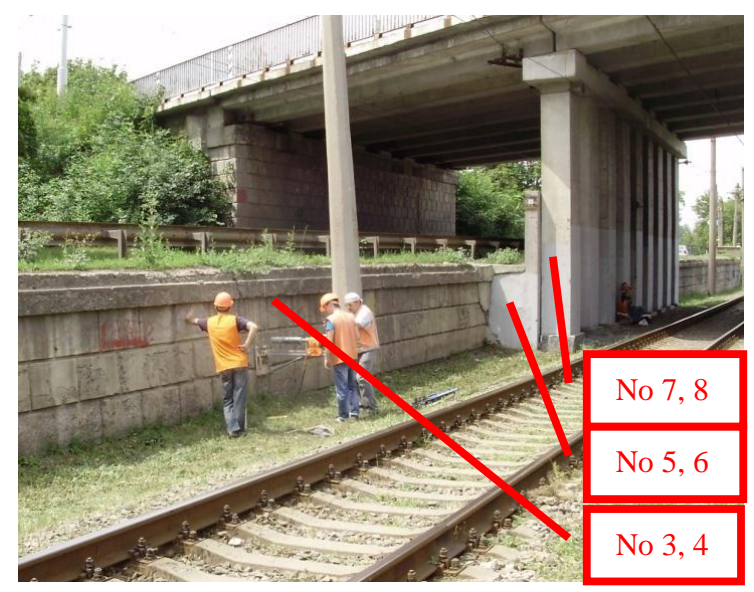

Fig. 4. Sample points on sustaining walls and supports

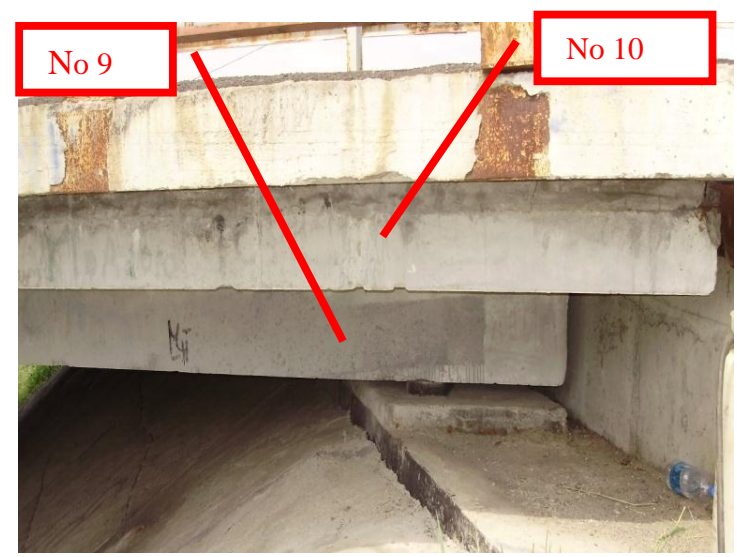

Fig. 5. Measuring strengths and potentials on the main plate and console

Core samples were selected from the places with ciphers No. 1 to 8 , of which test cylinders were made in the laboratory to determine their compressive strength at fracture. Material strength values of plates No. 9-10 were investigated by the non-destructive method (rebound hammer test). The test results are given in Table 1.
Table 1. Material measurement results of overpass structures

\begin{tabular}{|c|c|c|}
\hline Sample code & Strength $R, \mathrm{MPa}$ & Potential $U, \mathrm{~V}$ \\
\hline No 1 & 16.56 & 0.07 \\
\hline No 2 & 17.51 & 0.12 \\
\hline No 3 & 18.69 & 0.19 \\
\hline No 4 & 21.92 & 0.27 \\
\hline No 5 & 28.43 & 0.37 \\
\hline No 6 & 29.35 & 0.41 \\
\hline No 7 & 40.04 & 0.62 \\
\hline No 8 & 44.6 & 0.75 \\
\hline No 9 & 45.88 & 0.83 \\
\hline No 10 & 48.4 & 0.91 \\
\hline
\end{tabular}

\section{DISCUSSION OF RESULTS}

Following the data presented in Table 1, the strength of the top paving slab samples is not much greater than the bottom. The sample strength of the internal parts of other pathway constructions is considerably $(1,5 \div 2$ times $)$ higher than the strength of the outer part samples. We can see that the concrete strength of the main slab, its outer cantilever and cement slurry have decreased significantly to the supporting part. Since it is the support part that the leakage current passes through, therefore, the removal of $\mathrm{Ca}^{2+}$ cations (leaching) takes place and the strength of concrete decreases, as can be seen from stalactite-like calcite formations below the beam (Fig. 6). The remaining strength values correlate with the compressive strength determined for concrete samples in the laboratory (Fig. 7).

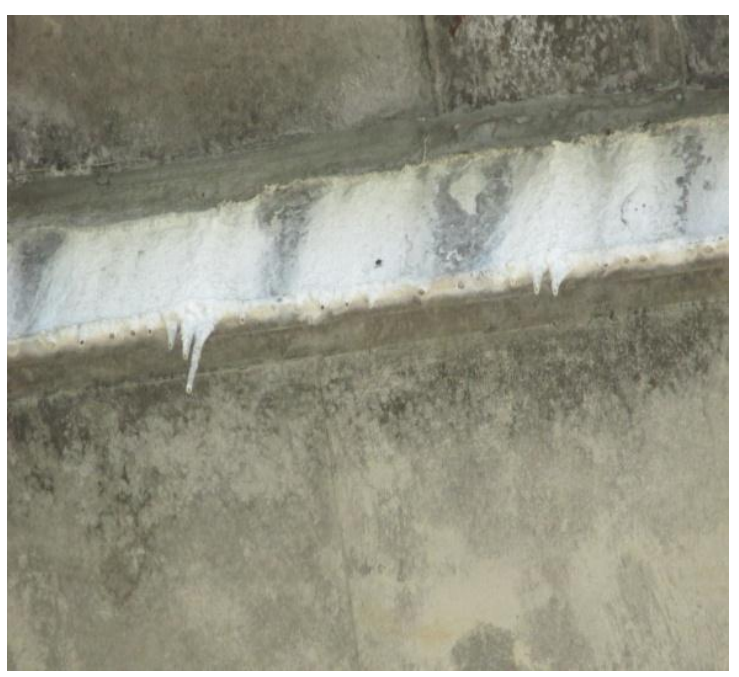

Fig. 6. Concrete leaching of over-bridge constructions 


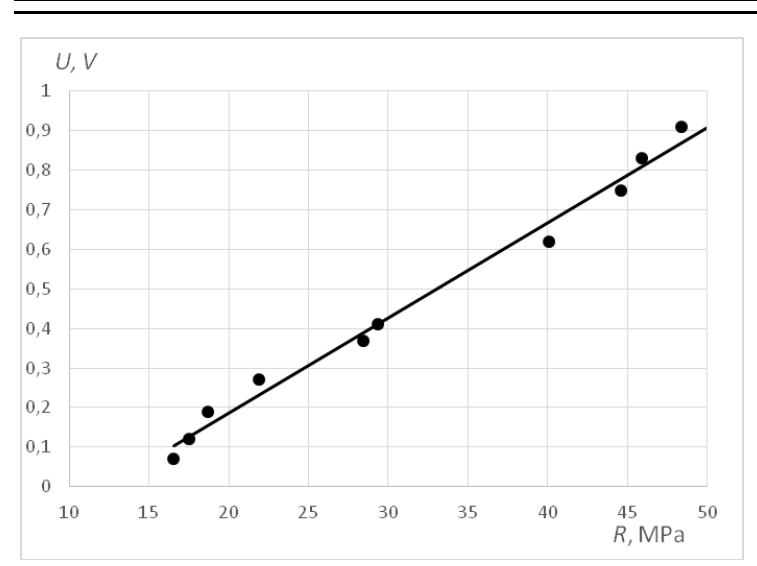

Fig. 7. Strength dependence on electric potential

The data in Fig. 6 show that the value decrease in $U$ potential, determined on the field structure, reflects $R$ concrete strength decrease. This relationship can be expressed in a linear relationship

$$
R=0.0241 \cdot U-0.2961 .
$$

The obtained correlation coefficient $\left(\mathrm{R}^{2}=0.9888\right)$ shows an excellent degree of approximation of the experimental and calculated data.

The electrical potential presence can technically be explained from the point of view of colloidal chemistry. When placing any solid particle in the electrolyte solution, a double electric layer forms around it. This layer is similar to a capacitor, one of the plates of which is formed out of charges at the surface of a solid particle, and the second is formed out of opposite sign ions adsorbed from an electrolyte (the so-called proevoions). Some part of the proevoions that are located in the immediate vicinity of the surface are connected to it by strong forces of electrostatic attraction. The remaining counterions form the so-called diffuse part of the double electric layer. When water flows through the capillaries and pores, this part of the counterions is entrained in water accumulating in the places of water evaporation from the concrete surface. Consequently, an excess of positively charged particles, which is recorded by a measuring device, occurs in one part of the structure and the presence of potential difference occurs in the other, that is, in negatively charged particles.

Bridge, tunnel, pipe concrete constructions are placed in the open air under the direct influence of rain and meltwater. When water flows through concrete, cement hydration products also dissolve, which bind sand particles and coarse aggregate together. Operational loads and vibrating effects lead to the appearance of concrete microcracks, where water penetrates, dissolving more and more portions of the binder. Following several decades of concrete construction operation, the difference in ion concentration in the pores becomes less and less noticeable, which leads to a decrease in the potential registered value.

In order to confirm the mechanism described above for reducing the potential difference with decreasing the strength of concrete, the selected samples from the overpass structures were examined by the method of X-ray phase analysis. $\mathrm{X}$-ray phase analysis was performed with the help of a modernized ДРОН-3 X-ray diffractometer with the ability to write data to a PC with the help of DIFWIN1special application. An X-ray tube of $1,6 \mathrm{BCB} 27-\mathrm{Fe}$ with an iron cathode was used. $2 \theta$ angle interval was $7-80^{\circ}$, voltage was $30 \mathrm{kV}$, current was $20 \mathrm{~mA}$. The sample and the counter of the $\mathrm{x}$-ray impulses rotate automatically in a horizontal plane around the common vertical axis of the goniometer with $V_{m f}=2 V_{\text {rev }}$ ratio of the velocities. In this case, the counter measures the intensity of the diffraction pattern sequentially under different angles of reflection. The counter reading is recorded on the PC screen. Spectral registration was conducted in the following mode: recording speed is 1 degree per $10 \mathrm{~mm}$ of paper tape; sample rotation rate is $1 \mathrm{deg} / \mathrm{min}$; record start angle is $5^{\circ}$, end angle is $43^{\circ}$, voltage is $\mathrm{kV}$, current is $25 \mathrm{~mA}$. To receive accurate quantitative content X-ray spectra were processed with a help of a special calibration program. The calibration program was previously created using the standard samples which content is known. Analyzing X-ray diffraction spectra, diffraction maxima were identified using the data of [18].

The X-ray diffraction pattern of the samples from the outer part of the old retaining wall (Figure $8, a)$ shows a lower line intensity typical for portlandite $(4.93 \AA, 2.63 \AA, 1.93 \AA)$, ettringite $(9.73$ $A, 5,61 \AA, 3.88 \AA$ ), but individual peaks of hydroaluminates $(10.6 \AA, 7.9 \AA, 2.88 \AA, 2.53 \AA$, $2.48 \AA)$, as well as low $(12.5 \AA ; 3.08 \AA, 2.8 \AA, 1.83$ A) and high-basic $(8 \AA, 3.07 \AA, 2.8 \AA, 1.83 \AA)$ calcium hydrosilicates (CHS) and calcite $(3.03 A$, $2.088 \AA, 1.91 \AA, 1.869 \AA$ ) are expressed to the bigger extent in intensity than in the inner part (Fig. $8, b)$. Silicon oxide level $(4.24 \AA, 3.34 \AA, 2.45 \AA$, $2.28 \AA, 1.82 \AA, 1.54 \AA$ ) remains almost the same. Greater line intensity typical for portlandite, ettringite, and hydroaluminates is found on the $\mathrm{X}$ ray pattern samples from the outer part of the new sustaining wall (Fig. 8,c). Low and high-basic CHS and calcite are also more expressed in intensity than in the interior part. Silicon oxide level remains almost the same. The X-ray sample patters from the outer and interior parts of the supports (Fig. 8, $d, e$ ) are practically identical in line intensity, typical for portlandite, calcium hydronosulfonic aluminate and hydroaluminates, low and high-basic CHS, calcite and silicon oxide. Ettringite level is slightly bigger in the interior part of the support. Higher line intensity typical for portlandite, ettringite and hydroaluminates, as well as low-basic calcium hydrosilicates, is detected on the X-ray spectra of 
the specimens from the lower part of the support (Fig. 8, $g$ ). The level of high-basic CHS and calcite is the same from the top part of the abutment (Figure $8, f, h$ ), and silicon oxide in the bottom part of the abutment is smaller (lower line intensity).

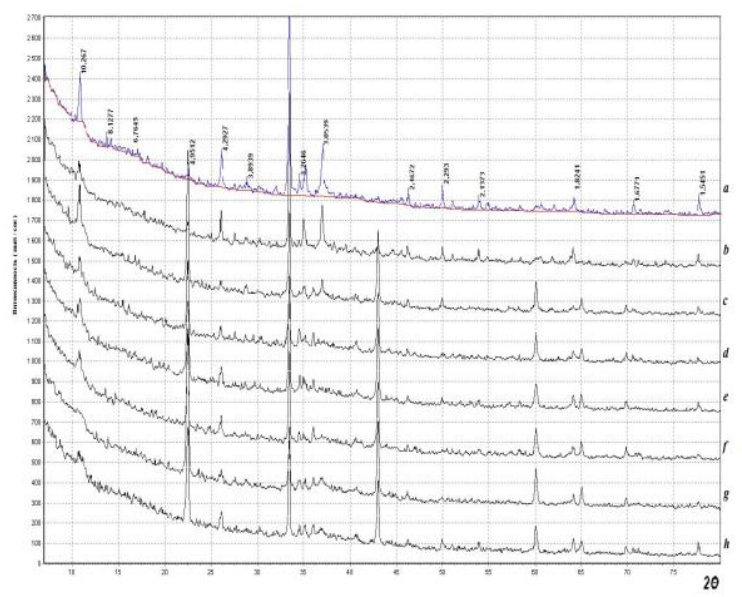

Fig. 8. X-ray sample patterns of over-bridge concrete

Thus, the method of X-ray phase sample analysis confirmed the decrease in the number of cement hydration basic products, according to concrete aging and leaching. The received equation (1) can serve as a theoretical model for predicting changes in the concrete strength based on electrical potential measurements. For this, it is necessary to reveal coefficient physical meaning in the equation (1), which may serve as the goal of subsequent researches.

\section{CONCLUSIONS}

It has been shown that the most important component of monitoring the state of infrastructure facilities can be non-destructive monitoring methods based on measuring the electrical characteristics of the material, in particular, the potential. When the concrete strength is twice reduced, the value of the potential changes 10 times, which makes it possible to determine the critical value with sufficient accuracy where the structure operational properties require immediate restoration in the form of repair or reinforcement. The changes in the amount of portlandite, etrengite and other neoplasms have been confirmed using the method of X-ray phase analysis of concrete samples causing changes of concrete electrical properties. The performed researches serve as additional theoretical and experimental bases to apply them in the existing diagnosis system of the structures that are operated for a long time. The said monitoring method allows to determine an initial structure change before the serious damage occurs. The lowcost, simplicity, and reliability are the advantages of developed method with the $0.01 \mathrm{mV}$ admission, and $0.08 \%$ fault. This method can also find a wide application in an industry for testing the underground structures which are accessible only from one side.

\section{REFERENCES}

1. ASTM C876-91, Standard Test Method for Half-cell Potentials of Uncoated Reinforcing Steel in Concrete, American Standards for Testing Materials, Reapproved 1999.

2. Ayswarya KS, Johnson AM, Chaithanya, Prasad D, Krishnan DR, Radhika Nair NJ. Evaluation of Bridge Performance Using Non-Destructive Testing - A Review. International Advanced Research Journal in Science, Engineering and Technology, 2016; 5 (1): 518. http://dx.doi.org/10.17148/IARJSET.

3. Bakhramov O, Kaps C, Samigov N. Anwendung von Lichtoptischen Feuchte-Sensor in der Baupraxis. Proceeding 18. Internationale Baustofftagung, 2012:1143-1150.

4. Bakhramov O, Kaps Ch, Samigov N. Lichtoptischer Feuchte-Sensor und seine Anwendung. Proceeding 17. Internationale Baustofftagung, 2009:1121-1126.

5. Girtler J. Identyfication method of technical state of the objects on the ground of estimation of their work. Diagnostyka, 2001; 25: 5-12.

6. Harnisch J, Dominik A, Raupach M, Koch S. Entwicklung eines Sensorsystems für die tiefengestaffelte, kontinuierliche Wassergehaltsbestimmung in Mauerwerk. Proceeding 16. Internationale Baustofftagung, 2006, 2: 1213-1220.

7. Hecht C, Grüner M, Neubauer G, Dreyer J. Messung von Verdunstungsmengen auf Bauteiloberflächen als Begleitung von Sanierungen Proceeding 16. Internationale Baustofftagung, 2006: 1281-1288.

8. Kurumisawa K, Nawa T. Electrical Conductivity and Chloride Ingress in Hardened Cement Paste. Journal of Advanced Concrete Technology, 2016;14 (3): 8794. http://dx.doi.org/10.3151/jact.14.87.

9. Lübeck A, Gastaldini ALG, Barin DS, Siqueira HC. Compressive strength and electrical properties of concrete with white Portland cement and blastfurnace slag. Cement and Concrete Composites, 2012;34(3):392-399.

http://dx.doi.org/10.1016/j.cemconcomp.2011.11.017

10. Michelle R. Nokken, R. Doug Hooton. Electrical Conductivity Testing. American Concrete International, 2006: 58-63.

11. Pratanu Ghosh, Quang Tran. Correlation Between Bulk and Surface Resistivity of Concrete. International Journal of Concrete Structures and Materials, $2015 ; \quad 9(1): 119-132$. http://dx.doi.org/10.1007/s40069-014-0094-z.

12. Rama Mohan Rao. P, Vinothkumar S. Assessment of Strength and Electrical resistance of Ternary blend concrete. International Journal of ChemTech Research, 2015; 7(4):2034-2040.

13. Rucka M, Wilde K. Non-destructive diagnostics of concrete cantilever beam and slab by impact echo method. Diagnostyka, 2010; 3(55): 63-68.

14. Sanish KB, Narayanan Neithalath, Manu Santhanam. Monitoring the evolution of material structure in cement pastes and concretes using electrical property measurements. Construction and Building Materials, 2013;49:288-297. https://dx.doi.org/10.1016/j.conbuildmat.2013.08.038

15. Rehman S, Ibrahim Z, AliMemon S, Jameel M. Nondestructive test methods for concrete bridges: A review. Construction and Building Materials, 2016; 
107:58-86.

https://dx.doi.org/10.1016/j.conbuildmat.2015.12.011

16. Shen $\mathrm{P}, \mathrm{Lu} \mathrm{L}, \mathrm{He} \mathrm{Y}$, Wang $\mathrm{F}, \mathrm{Hu} \mathrm{S}$. Hydration monitoring and strength prediction of cement-based materials based on the dielectric properties. Construction and Building Materials, 2016; 126: 179189.

https://dx.doi.org/10.1016/j.conbuildmat.2016.09.030

17. Sklodowski M, Pininska J, Lukaszewski P, Bobrowska A. Application of Rayleigh wave to diagnostics of degradation of historic construction materials. Diagnostyka, 2011; 3(59): 19-24.

18. Snellings R. X-Ray Powder Diffraction. In: Scrivener K, Snellings R, Lothenbach B, eds. A Practical Guide to Microstructural Analysis of Cementitious Materials. CRC Press; 2017.

19. Starrs G, McCarter WJ, Chrisp TM. Characterisation of PFA using impedance techniques. Proceeding of the $11^{\text {th }}$ International Congress on the Chemistry of Cement. - 11-16 May 2003, Durban, South Africa: 370-379.

20. Verstrynge E, Orlowsky J, Harnisch J, Raupach M. Calibration of Sensors for Measuring the Humidity of the Masonry of the Cathedral in Aachen. Proceeding 16. Internationale Baustofftagung, 2006 2:751-758.

21. Xu D, Hu X-Y, Shan C-L, Li R-H. Landslide monitoring in southwestern China via time-lapse electrical resistivity tomography. Applied Geophysics, 2016;13(1):1-12. http://dx.doi.org/10.1007/s11770-016-0543-3.

Received 2017-10-20

Accepted 2017-12-07

Available online 2017-12-18

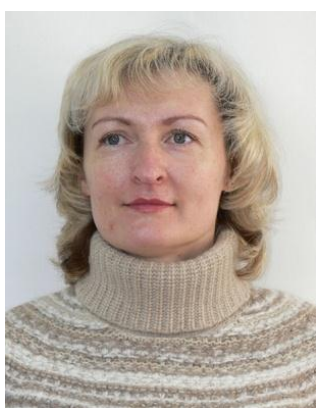

Liudmyla TRYKOZ, Ph.D., D.Sc. is professor at the Department of Building Materials, Constructions and Structures, Ukrainian State University of Railway Transport. Main directions of scientific research: research of the structure and properties of disperse systems and materials; development in the field of waste utilization in the production of building materials; diagnostic the state of engineering structures; the ground and roadbad stabilization.

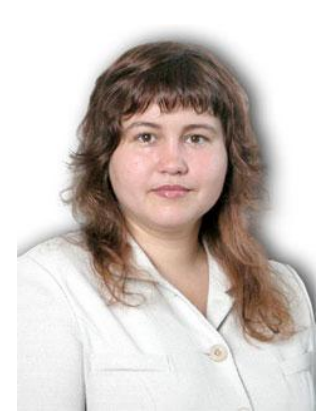

Svetlana KAMCHATNAYA, $\mathrm{Ph} . \mathrm{D}$. , is associate professor Department of Track and Track Facility, Ukrainian State University of Railway Transport. Main directions of scientific research: construction of the roadbad, durability of reinforced concrete structures.

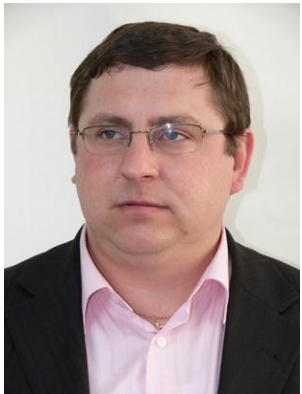

Vitalii LYUTY, Ph.D., is associate professor at the Department of Building Materials, Constructions and Structures, Ukrainian State University of Railway Transport. Main directions of scientific research: research of long cyclic mechanical actions on concrete, reinforced concrete and stone structures of engineering structures; development of constructive and technological solutions for the repair and reinforcement of engineering structures structures; inspection and testing of engineering structures.

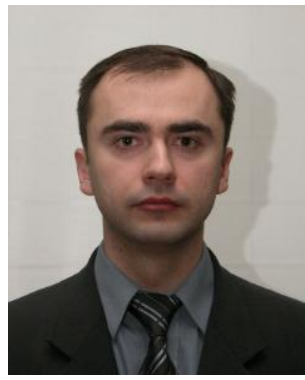

Dmytro BORODIN, Ph.D., is associate professor at the Department of Descriptive Geometry and Computer Graphics, Ukrainian State University of Railway Transport. Main directions of scientific research: the use of automated systems in the design, information systems and technology.

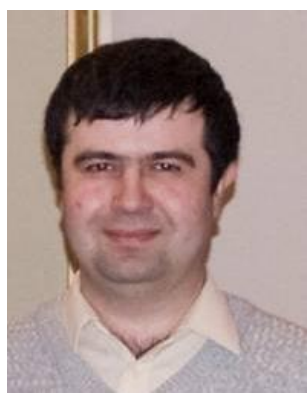

Armen ATYNIAN, Ph.D., Associate Professor Department of Construction Technology and Building Materials, O.M.Beketov National University of Urban Economy, Kharkiv, Ukraine. Main directions of scientific research: production of environmentally friendly building materials for the manufacture of heat-insulating and fire retardant molded products; energy-saving technologies for heat and sound insulation of building structures 